\title{
Assistente social ou repórter? Fiscal do trabalho ou policial?
}

Silvia Cristina Yannoulas

Universidade de Brasília (UnB)

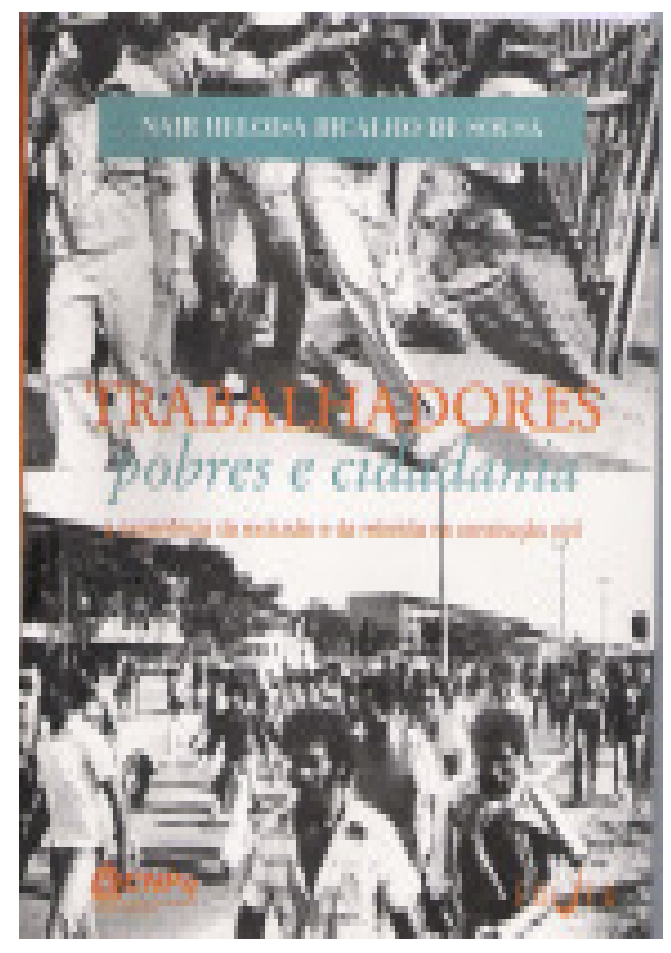

RESENHA: Assistente social ou repórter? Fiscal do trabalho ou policial?

SOUSA, Nair Heloisa Bicalho de. Trabalhadores pobres e cidadania: a experiência da exclusão e da rebeldia na construção civil. Uberlândia: EDUFU, 2007.258 p.

BOOK REVIEW: Social Worker or Reporter? Labor Inspector or Police Officer?

SOUSA, Nair Heloisa Bicalho de. Poor Workers and Citizenship: Exclusion and Rebellion in Civil Construction. Uberlândia: EDUFU, 2007. $258 \mathrm{p}$. 
A mais recente obra da professora Nair Heloísa Bicalho de Sousa "discorre sobre o processo de formação do sujeito coletivo na construção civil com base nas experiências dos trabalhadores no mundo privado e nos conflitos vivenciados no cotidiano do trabalho, nos quebra-quebras e nas greves..." A autora propõe como hipótese central "a capacidade que têm [o sujeito coletivo] de configurar uma identidade de interesses que permita instrumentalizar a luta coletiva pela criação de direitos com base nas experiências do mundo privado, nos conflitos vivenciados no cotidiano de trabalho, nos quebra-quebras e nas greves."

O lócus privilegiado da pesquisa se concentrou nos canteiros de obra, no Distrito Federal e Entorno, mas também em Natal, João Pessoa, Belo Horizonte, Rio de Janeiro e São Paulo. A pesquisa é caracterizada como qualitativa, pois coloca como eixo fundante a interpretação do material de campo coletado através da utilização de técnicas de observação direta em visitas aos canteiros de obra e de entrevista (cerca de 200). Os atores estratégicos entrevistados individual e coletivamente foram os operários, as operárias, os dirigentes sindicais da categoria, e os diferentes gestores da produção na construção civil. Complementa essa análise qualitativa certa quantificação dos fenômenos tratados através do levantamento documental em entidades como IBGE, CNTI, CUT, sem perder o enfoque qualitativo.

O livro, que consta de 258 páginas, está organizado em apresentação, introdução, cinco capítulos, e conclusão, seguidos das referências bibliográficas e documentais. Após explicar a trajetória realizada nos seus aspectos epistemológico, metodológico e teórico (apresentação e introdução), a autora se debruça, sucessivamente:

a) no tratamento da vida familiar dos trabalhadores como o espaço da conformação dos afetos mais íntimos, da construção da solidariedade com parentes e vizinhos, e da afirmação dos valores morais em torno do mandato de provedor familiar como eixo da definição da identidade privada e paralelamente suporte da vida pública.

b) no cotidiano do canteiro da obra, considerado o espaço privilegiado para a constituição da sociabilidade operária, e também para a aparição dos sentimentos de submissão e de rebeldia nas relações dos operários com os gestores da produção;

c) no desenvolvimento da identidade operária momentânea, na qual os trabalhadores vão percebendo interesses comuns e forjando estratégias coletivas em favor da defesa de seus direitos, utilizando diversas formas como o "nó-cego" ou o "quebra-quebra", entendidas como linguagem de expressão do protesto em relação à nãocidadania dos trabalhadores da construção; d) na emergência e na gradativa consolidação do sujeito coletivo através das greves e outras ações da categoria em Brasília, considerando especialmente momentos de cristalização das identidades momentâneas e de emergência do sujeito coletivo, como foram as greves realizadas em 1979 - caso ilustrativo de manobra sindical deslegitimada pelas bases, e em 1990 - caso ilustrativo da mobilização nos próprios canteiros de obra e do surgimento do movimento de base da construção civil;

e) na construção da cidadania entre esses os trabalhadores, explorando as representações sociais do direito, da lei e da justiça na perspectiva da cidadania operária (Capítulo "Direito, lei e justiça"); e, finalmente,

f) num olhar em retrospectiva sobre o percurso do estudo, reconhecendo seus pontos de destaque e tecendo relações com as teorias que orientaram a procura e a análise realizada - a centralidade do conceito de configurações de classe (tributado a Eder Sader), o não-reconhecimento na condição de sujeitos de reivindicações legítimas dos trabalhadores pobres urbanos (Vera Telles), o sentimento de dignidade violentada (Laís Abramo), os meios de pressão e expressão desse sentimento (Michelle Perrot), a cidadania coletiva diferenciada (Célia Paoli), a constituição do sujeito coletivo de direito (José Geraldo Sousa Júnior), e de uma cultura da cidadania (Marilena Chauí).

Com base nesse imponente arcabouço teórico, Bicalho de Sousa analisa com maestria "o processo de formação do sujeito coletivo dos trabalhadores da construção civil", propondo a articulação desse processo em três níveis articulados entre si:

a) no âmbito da constituição de uma identidade coletiva operária, desenvolvida principalmente no cotidiano de trabalho nos canteiros de obra, onde a pressão e a reivindicação dos diferentes grupos constroem o modo de ser da classe;

b) no campo do conflito, quando os operários vivenciam os sentimentos de revolta e humilhação face à injustiça presente no canteiro de obra, organizam a revolta e assinalam momentos de ruptura significativos; e

c) na capacidade de criação de direitos, através da afirmação da cidadania num processo de declaração pública dos seus direitos e obtenção do reconhecimento público destes.

Gostaríamos de salientar dois aspectos contidos na obra em questão. Em primeiro lugar, a análise da aplicação dos quebra-quebras nos canteiros de obra explica a violência como conseqüência da arbitrariedade e da falta de resposta às demandas geradas pela exclusão, privação e humilhação vivenciadas cotidianamente pelos operários da construção civil: 
"a luta por direitos através dos quebra-quebras revela a ausência de organismos institucionalizados de representação legítima e negociação, deixando visível a condição de não-cidadania dos trabalhadores." A estratégia, denominada pela autora de "cidadania do protesto", estaria indicando a formação de uma identidade coletiva momentânea, exigindo direitos básicos não respeitados.

Em segundo lugar, e diferentemente dessa cidadania do protesto que eclodiu diante de circunstâncias em que se fez necessário a coesão coletiva e a ação imediata, a análise do significado das greves ilustraria o aprendizado de classe no processo de conformação do sujeito coletivo. "O processo de constituição do sujeito coletivo tal como proposto neste trabalho abrange três dimensões qualitativamente distintas e articuladas - identidade coletiva, conflito e capacidade de criação de direitos - de modo a permitir a configuração deste na sua totalidade." Isto é, encontram-nos frente ao sujeito coletivo quando os antagonismos entre os diferentes atores estão explicitados, e o operariado é reconhecido publicamente (pela sociedade e pelo Estado) como sujeito de direito, dotado da capacidade de negociar e defender os interesses da categoria.

\section{Socióloga ou antropóloga? Advogada ou cientista política?}

O livro é produto da tese defendida no contexto do Curso de Doutorado em Sociologia da Universidade de São Paulo (USP). Entretanto, não podemos dizer que se trate de uma obra exclusivamente sociológica. A autora percorre essas arenas com tranquiilidade e tece relações entre as disciplinas com grande fluidez. Sua pequisa qualitativa combina severidade metodológica, envolvimento político-social, e audácia epistemológica. Nair não admite limitações de especialização disciplinar, atravessa com rebeldia as fronteiras artificiais entre as áreas do conhecimento e aproveita frutíferamente o melhor de cada uma das disciplinas das ciências sociais que nutrem os estudos do trabalho na abordagem de seus queridos objetos-sujeitos de pesquisa. Também não se trata de uma obra exclusivamente acadêmica, redigida numa linguagem pouco acesível aos leigos. Ao contrário, Sousa escreve de maneira clara, reproduzindo na escrita suas qualidades docentes. Assim, o livro que ora resenhamos com grande prazer, é indicado como leitura de referência fundamental para todos os/as interessados/as na sociologia do trabalho, mas também na política de trabalho, no direito trabalhista, e nos movimentos sociais.

Finalmente, destacamos que o livro reúne dois componentes que, são fundamentais no desenvolvimento das ciências sociais: a) trabalha a questão da cidadania na análise teórica das configurações e dos conflitos vivenciados pela classe trabalhadora, incluindo esse eixo entre os mais relevantes para o avanço do conhecimento científico em matéria dos estudos do ou sobre o trabalho; e paralelamente,

b) pretende colocar as ciências sociais ao serviço do bem-estar da população mais pobre e excluída, cumprindo assim com um dos objetivos sociais da universidade, qual seja o desenvolvimento de sociedades politicamente democráticas e socialmente justas.

\section{Silvia Cristina Yannoulas}

Doutora em Ciências Sociais pelo Programa Conjunto FLACSO/Brasil-UnB (Faculdade Latino-Americana de Ciências Sociais/Sede Acadêmica Brasil e Universidade de Brasília)

Professora adjunta no Departamento de Serviço Social da Universidade de Brasília (UnB)

\section{UnB}

Departamento de Serviço Social

Campus Universitário

ICC Centro - Asa Norte

Brasília - Distrito Federal

CEP: 70910-900 